\title{
Real Time Based Recommendation System for Taxi Ride Sharing
}

\author{
Amruta N. Deshmukh ${ }^{1}$, K. K. Chhajed ${ }^{2}$ \\ ${ }^{1}$ Student ME 2nd CSE P. R. Pote (Patil) College of Engineering \& Management, Amravati, Maharashtra, India \\ ${ }^{2}$ Assistant Professor P. R. Pote (Patil) College of Engineering \& Management, Amravati, Maharashtra, India
}

\begin{abstract}
In today's fast moving world, people face numerous problems associated in getting a taxi in one or more ways like waiting time, higher taxi fares etc. With the help of taxi sharing system, the issues pertaining to getting a taxi and waiting for a taxi are resolved at a better level. The passengers as well as taxi drivers are benefited by implementing the taxi sharing system. Furthermore this system facilitates sustainable development through saving energy consumption and suffices passenger transport. In this project, further restructuring of the taxi sharing system has been done in order to get the optimum benefits such as, incorporating the credibility of taxi drivers and riders into the taxi searching and scheduling, preference to regular customers \& introducing social constraints, such as gender preference, habits preference. Ex some people may refer co-passenger who do not smoke
\end{abstract}

Keyword: Spatial databases, taxi-sharing, ridesharing, urban computing, intelligent transportation systems

\section{Introduction}

The uncontrolled and ill planned growth of urban centers has resulted in a number of problems like traffic congestion, shortages of water and electricity, deteriorating environment and public health. The growing cities have generated the high levels of demand for travel by motor vehicles in the cities. To match the increasing travel demand commensurate efforts have not been made to develop the mass transport systems.

Taxi is an important transportation mode between public and private transportations, delivering millions of passengers to different locations in urban areas. However, taxi demands are usually much higher than the number of taxis in peak hours of major cities, resulting in hat many people spend a long time on road sides before getting a taxi. Increasing the number of taxi is seems an obvious solution. But it brings some negative effects, e.g., causing additional traffic on the road surface and more energy consumption, and decreasing taxi driver's income (considering that demands of taxis would be lower than number of taxis during off-peak hours). [1]

With rapid population growth and city development, traffic congestion has become an important issue, especially in large cities. The 2012 Annual Urban Mobility Report developed by the Texas Transportation Institute (Schrank et al., 2012) estimates that (a) The amount of delay endured by the average commuter was 38 hours, up from 16 hours in 1982 , and (b) the cost of congestion is more than $\$ 120$ billion, nearly $\$ 820$ for every commuter in the United States. [2]

"Real-time" ridesharing will be defined as "a single, or recurring rideshare trip with no fixed schedule, organized on a one-time basis, with matching of participants occurring as little as a few minutes before departure or as far in advance as the evening before a trip is scheduled to take place". In addition to the proposed definition, the use of the term "realtime" ridesharing may refer to the package of technologies and features that are typically used to enable this type of service

In recent years, an innovative rideshare service relying heavily on mobile phone technologies known as "real-time" ridesharing, or "dynamic" ridesharing has gained in popularity. Traditionally, rideshare arrangements between two or more unrelated individuals for commuting purposes have been relatively inflexible, long-term arrangements. The increasing complexity of work and social schedules and the related increase in vehicle trip complexity, such as trip chaining, is assumed to have made this type of commuting arrangement less desirable. Real-time ridesharing attempts to provide added flexibility to rideshare arrangements by allowing drivers and passengers to arrange occasional shared rides ahead of time or on short notice. The addition of this service innovation presents a number of opportunities to overcome existing rideshare challenges, but also exacerbates certain rideshare challenges. [6]

Finite oil supplies, rising gas prices, traffic congestion, and environmental concerns have recently increased the interest in services that allow people to use personal automobiles more wisely. The demand for ride-sharing services, which aim to bring together travelers with similar itineraries and time schedules, has increased sharply in recent years. Rideshare providers across the globe are offering online notice boards for potential carpoolers, whether for daily commutes or for one-time trips to festivals, concerts, or sports events. Some online services, such as Nuride, provide incentives like restaurant coupons, gift certificates, or retail sales discounts to participants.[7]

\section{Literature Survey}

In 2012 Arpita had introduced carpooling system. Transportation is a major issue these days. One of the most used means of communication in roadways. One of the major forms of road transport consists of the private passenger car. These cars are generally used with only a single rider. An overabundance of cars creates various problems which 


\section{International Journal of Science and Research (IJSR) \\ ISSN (Online): 2319-7064}

Index Copernicus Value (2013): 6.14 | Impact Factor (2015): 6.391

include increased traffic, increase pollution, parking congestion and many more. Car sharing aims at solving this problem by targeting the empty seats in the private cars. Employees of the same area or the students going to the same school can carpool. This can be done as the know each other and can communicate. But when going on an intercity trip you are not aware if some other person also intends to make the same journey. Thus the applications helps you in seeing people and journey schedules and make an informed decision about do you wish to travel alone or save money and travel with a safe company[8]

In 2012 Jung, Jaya krishnan, and Park [3] have defined Realtime ridesharing as dynamically utilizing the empty seats in passenger cars by assigning passengers on demand, which is quite different from the early version of carpooling projects that were not feasible for real-time response due to the lack of advanced information technologies. As real-time ridesharing projects have been successfully initiated, the potential benefits of ridesharing are expected to be substantial in reducing fuel consumption, carbon emissions, and traffic congestion. For customers, ride sharing can also reduce travel costs for driving and parking.

In 2013 Yan Huang, Ruoming Jin [4] had introduced the problem of large scale real-time ridesharing with service guarantee on road networks. Where in, servers and trip requests were dynamically matched while waiting time and service time constraints of trips are satisfied. They have proposed two basic algorithms: a branch-and-bound algorithm and an integer programing algorithm.

In 2015 Aarthi R1, [5] stated the advantages of ride sharing model. India being the second populous country in the world, having population about 1.1 billion with an overall density of 336 people per square kilometer. Indian public transport supports various mode of transport such as transport by land, water, air. More than $30 \%$ of Indian population is car owners. Traffic is mainly high during peak hours within the cities. In order to reduce traffic congestion, a real time ridesharing is proposed. Real-time ridesharing is an extension of carpooling to best suite one's preferences using the data collected from social networking.

\section{Proposed Methodology}

\subsection{Algorithm}

Optimization based match making algorithm for taxi sharing

1) Request set $\{r 1, r 2 \ldots \ldots \ldots . n\}$ place by the rider set $\{\mathrm{rd1}, \mathrm{r} 2, \mathrm{r} 3 \ldots \ldots \ldots . \mathrm{rdn}\}$.

2) Each request transfer to the server with its time stamp and ip address.

3) The request comes from various nodes with their ip addresses. The server send the notification to different drivers set $\{\mathrm{d} 1 \ldots . . \mathrm{dn}\}$.

4) The spatio-temporal index of taxis is built for speeding up the taxi searching process

5) The drivers $d$ accept or reject the request. If request is accepted, the server compute the latitude and longitude of the system, distance, denoted by dij, and travel time, denoted by tij, of the fastest path on the road network for each anchor node pair ci and cj. Both the distance and travel time is only computed once.

If $\mathrm{d} 1=$ true then

Notify $\mathrm{r} 1$.

6) The indexing server decide the drivers notification according to the timestamp. All notification list are sorted in ascending order of the associated timestamp $t$ and index gi:lv is updated dynamically.

$\mathrm{S}(\mathrm{t}, \mathrm{l})=\mathrm{dn}(\mathrm{t}) \cap \mathrm{d}(\mathrm{i})$.

Where,

r1.....rn $=$ request, $\quad r d 1 \ldots r d n=r i d e r, ~ t=t i m e s t a m p$, $\mathrm{i}=\mathrm{ip}, \mathrm{s}=$ indexing, $\mathrm{d}=$ distance.

The relevant ride confirmation sends to the rider

\subsection{Data flow diagram}

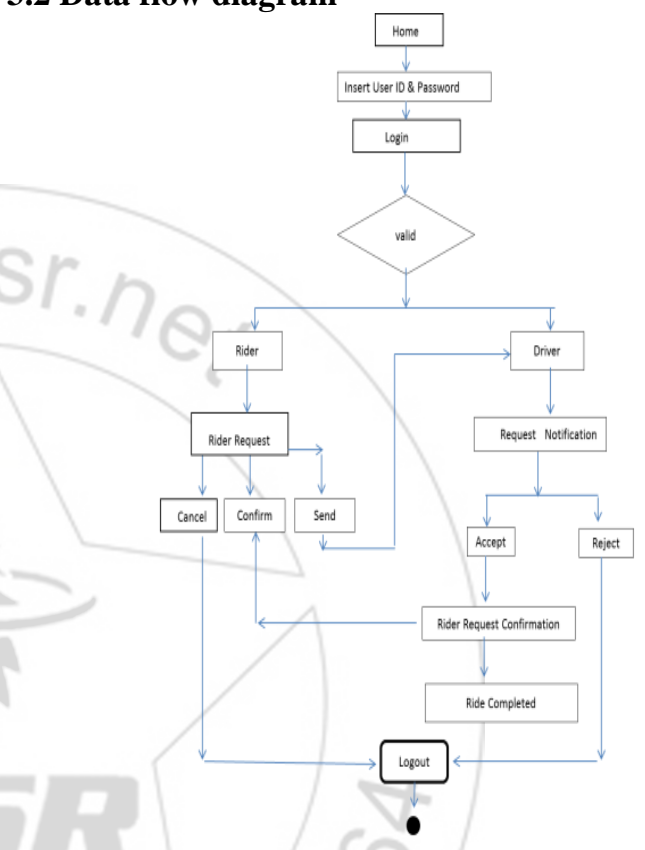

Figure 1: Data flow diagram for sytem

In this above data flow diagram of proposed system can show the overall flow of the system. In that rider and driver can enter their user id and password then enter in the system application then they can do their work. rider can send the request to the driver for the ride then driver give the notification to rider he can accept their request or not if request is accept then he can send the confirmation to the user and suppose he cannot accept the request to that particular user send the notification the request is rejected. Then ride is complete

\section{System Implementation}

$\mathrm{Rj}$ : A set of rejected requests during the simulation CR: A set of completed requests during the simulation

Tt: Travel time of passenger

Wt: Waiting time of passenger

$\mathrm{D}$ denotes the set of possible drivers, $\mathrm{R}$ the set of possible riders, and $U=D[R$ the set of all users. A trip schedule is a tuple tsu $=($ etstartu ; ltdest $\mathrm{u}$; lstart $\mathrm{d}$; ldest $\mathrm{d})$ describing user u's inferred earliest start time etstart u , latest arrival time ltdest $\mathrm{u}$, start location lstart $\mathrm{u}$, and destination ldest $\mathrm{u}$. $\mathrm{TS}=\mathrm{ftsu} 1$ 


\section{International Journal of Science and Research (IJSR) \\ ISSN (Online): 2319-7064}

Index Copernicus Value (2013): 6.14 | Impact Factor (2015): 6.391

tsung denotes the set of user trip schedules sent to the system.

To infer the time and geographical constraints, we use Open Street Map that is Google API data to deduce minimal path distances and times between two locations. $\mathrm{L}=\mathrm{fll}$; $\operatorname{lng}$ denotes the set of road node locations identied by their Lat\& Long coordinates. A path $=(\mathrm{li} ;::: ; \mathrm{j})$ is an ordered list $\mathrm{f}$ locations, and time() (resp. dist()) returns the driving path time (resp distance) for .

The path li;lj (resp. li; lj ) denotes a minimal time (resp. distance) path from li to $\mathrm{lj}$. For a driver trip schedule tsd, $d$ denotes the inferred driver path from start lstart $d$ to destination ldestd. For a rider trip schedule tsr, mpick $r$ denotes the inferred maximal path distance $r$ is willing to walk from his intended start lstart $r$ to a pick-up location lpick $\mathrm{r}$ on the driver path $\mathrm{d}$. Two performance measures are introduced in order to compare the system efficiency and performance, 3 Level-of-Service (LOS) index ( ) and Ridetime index ( ), compare the system efficiency in shared-ride transportation systems.

\section{Sending Request}

The new request $\{r 1, r 2 \ldots \ldots \ldots n\}$ place by the rider/ set $\{\mathrm{rd} 1, \mathrm{r} 2, \mathrm{r} 3 \ldots \ldots \ldots \ldots \mathrm{rdn}\}$. On the request sent, the request is handled by the server.

We use the Google API for getting the latitude and longitude of the two places. Every place having this latitude(lat) and longitude(lon). The googleapi returns these lat and lon numbers.

Further processing we need the distance between two places.

\section{Distance Calculation:}

lat1, lon1 = Latitude and Longitude of point 1 (in decimal degrees)

lat2, lon2 = Latitude and Longitude of point 2 (in decimal degrees)

unit $=$ the unit you desire for results where: ' $\mathrm{M}$ ' is statute miles (default)

$\mathrm{K}$ ' is kilometers

var radlat $1=$ Math.PI $*$ lat $1 / 180$

var radlat $2=$ Math.PI $*$ lat $2 / 180$

var theta $=$ lon1-lon2

varradtheta $=$ Math.PI $*$ theta $/ 180$

vardist $=$ Math.sin(radlat1) * Math.sin(radlat2) + Math.cos(radlat1) * Math.cos(radlat2) * Math.cos(radtheta);

dist $=$ Math.acos(dist)

dist $=$ dist $* 180 /$ Math.PI

dist $=$ dist $* 60 * 1.1515$

if (unit=="K") \{ dist $=$ dist $* 1.609344\}$

if (unit=="N") \{ dist $=$ dist $* 0.8684\}$

returndist

Now the request is dispatch to the drivers. The driver confirm that request and notification send to the specific customer by setting self-location. And waiting time sent to the customer.

The Waiting time $(\mathrm{Wt})$ Calculation:

var theta $=$ lon1-lon2

varradtheta $=$ Math.PI $*$ theta $/ 180$

vardist $=$ Math.sin(radlat1) $*$ Math.sin(radlat2) +

Math.cos(radlat1) * Math.cos(radlat2) * Math.cos(radtheta);

$$
\begin{aligned}
& \text { dist }=\text { Math } \cdot \operatorname{acos}(\text { dist }) \\
& \text { dist }=\text { dist } * 180 / \text { Math.PI } \\
& \text { time }=\text { dist } / \text { speed } \\
& \text { return time }
\end{aligned}
$$

To ease the computation load, here we only consider using the fastest path from one point to another during the insertion, though the new route may not be the shortest one in theory. Denote by - the travel time of the fastest path from one location to another location, and tw represents the time spent waiting for the passenger if the taxi arrives Q3 : o ahead of Q3 : pw : e. Eq. (4) gives the travel time delay, denoted by td after insertingQ3 : o betweenQ1 : o and Q2 : o

\section{Fare Sharing Percentage Calculation:}

Fs indicates the fare share.

$\mathrm{Fs}=\{\mathrm{fs} 1$. .fsn $\}$

$\mathrm{Rf}$ indicates the riders fare

$\mathrm{Rf}=\{\mathrm{rfl} \ldots \ldots \ldots \ldots . \mathrm{rfn}\}$

Sf indicates the Sum of fare

$\mathrm{Sf}=\{\mathrm{sfl} \ldots \ldots \ldots \ldots \mathrm{sfn}\}$

Ds indicates the percentage of fare share

$\mathrm{Ds}=\{\mathrm{ds} 1 \ldots \ldots \ldots . \mathrm{dsn}\}$

$\mathrm{Ds}=\{\mathrm{rf}\} /\{\mathrm{sf}\} * 100.0$

Net Fare Calculation:

$\mathrm{Nf}$ indicates the net fare

$\mathrm{Nf}=\{\mathrm{nf} 1$ $. n f n\}$

$\mathrm{Nf}=\mathrm{f}-((\mathrm{f} * \mathrm{ds}) / 100.0)$

\subsection{Result Analysis}

1.Excution time per request

Table 1: Execution time per ride request

\begin{tabular}{|c|c|c|}
\hline $\begin{array}{c}\text { No. of } \\
\text { Request }\end{array}$ & $\begin{array}{c}\text { Average Execution Time } \\
\text { Per Ride Request(MS) } \\
\text { existing system }\end{array}$ & $\begin{array}{c}\text { Average Execution Time } \\
\text { Per Ride Request(MS) } \\
\text { proposed system }\end{array}$ \\
\hline 1 & 6.7 & 6.2 \\
\hline 2 & 9.3 & 9.1 \\
\hline 3 & 7.5 & 6.8 \\
\hline 4 & 5.8 & 4.9 \\
\hline 5 & 5.7 & 5.3 \\
\hline 6 & 5.5 & 5.4 \\
\hline
\end{tabular}




\section{International Journal of Science and Research (IJSR) \\ ISSN (Online): 2319-7064}

Index Copernicus Value (2013): 6.14 | Impact Factor (2015): 6.391

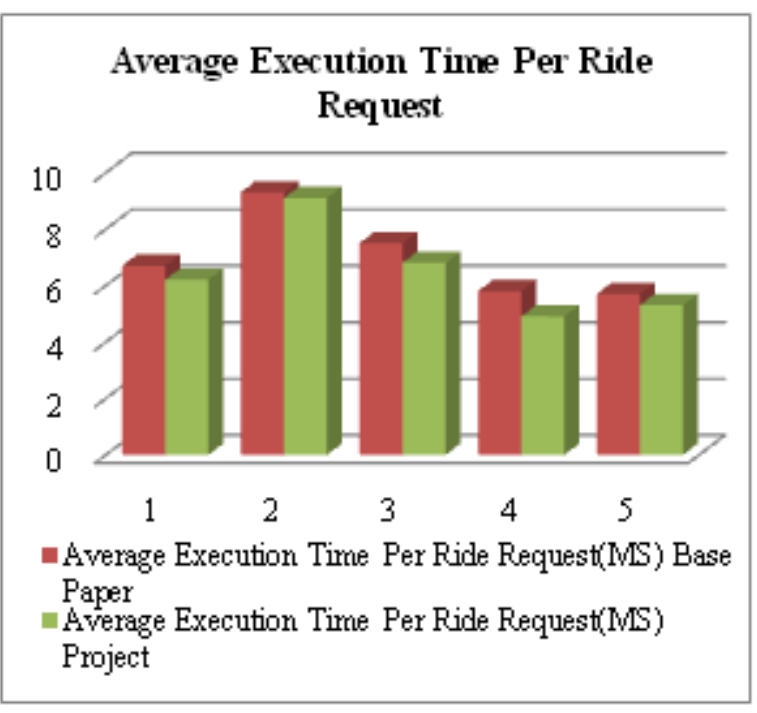

2. Satisfaction rate per user

Table 2:. Satisfaction rate per user

\begin{tabular}{|c|c|c|}
\hline User & $\begin{array}{c}\text { Satisfaction Rate in } \\
\text { Base Paper }\end{array}$ & Satisfaction Rate in Project \\
\hline $\mathrm{a}$ & 64.6 & 60 \\
\hline $\mathrm{b}$ & 70 & 70.1 \\
\hline $\mathrm{c}$ & 64.5 & 66.66 \\
\hline $\mathrm{d}$ & 64.3 & 64 \\
\hline $\mathrm{e}$ & 64.2 & 64 \\
\hline
\end{tabular}

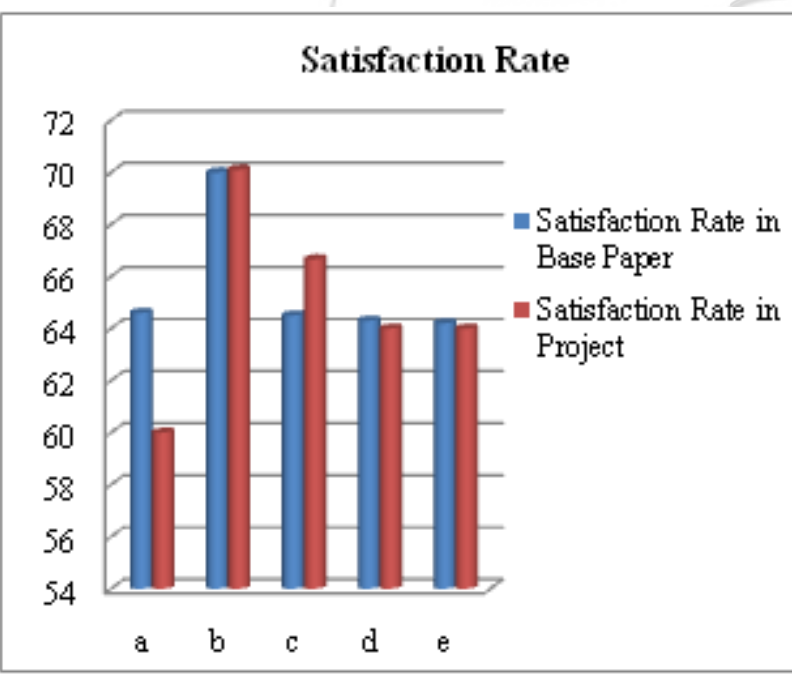

\section{Conclusion}

Real time taxi sharing system is very effective means to reduce pollution and the congestion of vehicles in cities. It also provides an eco-friendly way to travel. It also provides an opportunity to meet new people. System saves the total travel distance of taxis when delivering passengers. Our system can enhance the delivery capability of taxis in a city so as to satisfy the commute of more people. The system can also save the taxi fare for each individual rider while the profit of taxi drivers does not decrease compared with the case where no taxi sharing is conducted.

\section{Future Work}

In this proposed system the basic concept of taxi ride sharing through real-time request generation and its acceptance In future work may include request generation by third party for user who do not access the system due to unavoidable reasons. In this case user will be able to avail the facility without any hassles

\section{References}

[1] Shuo Ma, Yu Zheng, Senior Member, IEEE, and OuriWolfson, Fellow, IEEE"Real-Time City-Scale Taxi Ridesharing" IEEE TRANSACTIONS ON KNOWLEDGE AND DATA ENGINEERING, VOL. 27, NO. 7, JULY 2015.

[2] Huayu Xu1, Fernando Ordonez2, and Maged Dessouky_11Daniel J. Epstein Department of Industrial and Systems Engineering, University of Southern California, 3715 McClintock Avenue, GER 240, Los Angeles, CA 900892 Industrial Engineering Department, Universidad de Chile, Republica 701, Santiago, Chile "A Traffic Assignment Model For A Ridesharing Transportation Market"

[3] Jaeyoung Jung* Assistant Research Scientist, Ph. D. Institute of Transportation Studies University of California, Irvine Email: jaeyounj@uci.edu ,R. Jayakrishnan Professor Institute of Transportation Studies Department of Civil and Environmental Engineering University of California, Email: rjayakri@uci.edu ,Ji Young Park Associate Research Fellow, Ph. D.Office for convergence Technology The Korea Transport Institute 315, South Korea Email: parkjy@koti.re.kr “ Design and Modeling of Real-time Shared-Taxi Dispatch Algorithms ." Submission data: August 1, 2012

[4] Yan Huang, Ruoming Jin , FavyenBastani , Xiaoyang Sean Wang Computer Science and Engineering, University of North Texas1huangyan@unt.edu Computer Science, Kent State Universitsy2jin@cs.kent.edu , Massachusetts Institute of Technology3fbastani@mit.edu ,Computer Scicence, Fudan University 4xywangCS@fudan.edu.cn ."Large Scale Real-time Ridesharing with Service Guarantee on Road Networks"arXiv:1302.6666v1 [cs.DS] 27 Feb 2013

[5] Aarthi R1, PG Scholar, SNS college of Engineering, Kurumbapalayam, Coimbatore aarthisekaren@gmail.com “A Smart Real Time Ridesharing And Travel Assistance "International Journal Of Engineering And Computer Science ISSN:2319-7242 Volume 4 Issue 2 February 2015, Page No. 10264-10269

[6] AndrewAmey "Real-Time Ridesharing - The Opportunities and Challenges ofUtilizing Mobile Phone Technology to Improve Rideshare Services"

[7] Xing Wang "OPTIMIZING RIDE MATCHES FOR DYNAMIC RIDE-SHARING SYSTEMS" In Partial Fulfillment of the Requirements for the Degree Doctor of Philosophy in the School of Industrial and Systems Engineering Georgia Institute of Technology May 2013 


\section{International Journal of Science and Research (IJSR) \\ ISSN (Online): 2319-7064}

Index Copernicus Value (2013): 6.14 | Impact Factor (2015): 6.391

[8] Arpita Dixit, Shweta Bora, SonaliChemate, Nikita Kolpekwar "Real-Time Carpooling System for Android Platform

[9] R. Baldacci, V. Maniezzo, and A. Mingozzi, "An exact method for the car pooling problem based on lagrangean column generation," Oper.Res., vol. 52, no. 3, pp. 422439, 2004.1794 IEEE TRANSACTIONS ON KNOWLEDGE AND DATA ENGINEERING, VOL. 27, NO. 7, JULY 2015

\section{Author Profile}

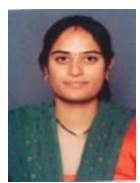

Amruta N. Deshmukh received her B.E (Computers) from Sandip Foundation Institute of Technology \& Research Centre. Nasik. Affiliated to Pune University, Pune, Maharashtra, India in 2013. Currently she is pursuing M.E. in Computer Science and Engineering from P. R. Pote College of Engineering And Technology Amravati, Maharashtra, India.

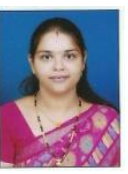

Prof. K. K. Chhajed received the B.E. degrees in Information Technology from Prof. Ram Meghe Institute of Technology \& Research in 2005 and completed ME (CSE) from Prof. Ram Meghe Institute of Technology \& Research, Amravati.

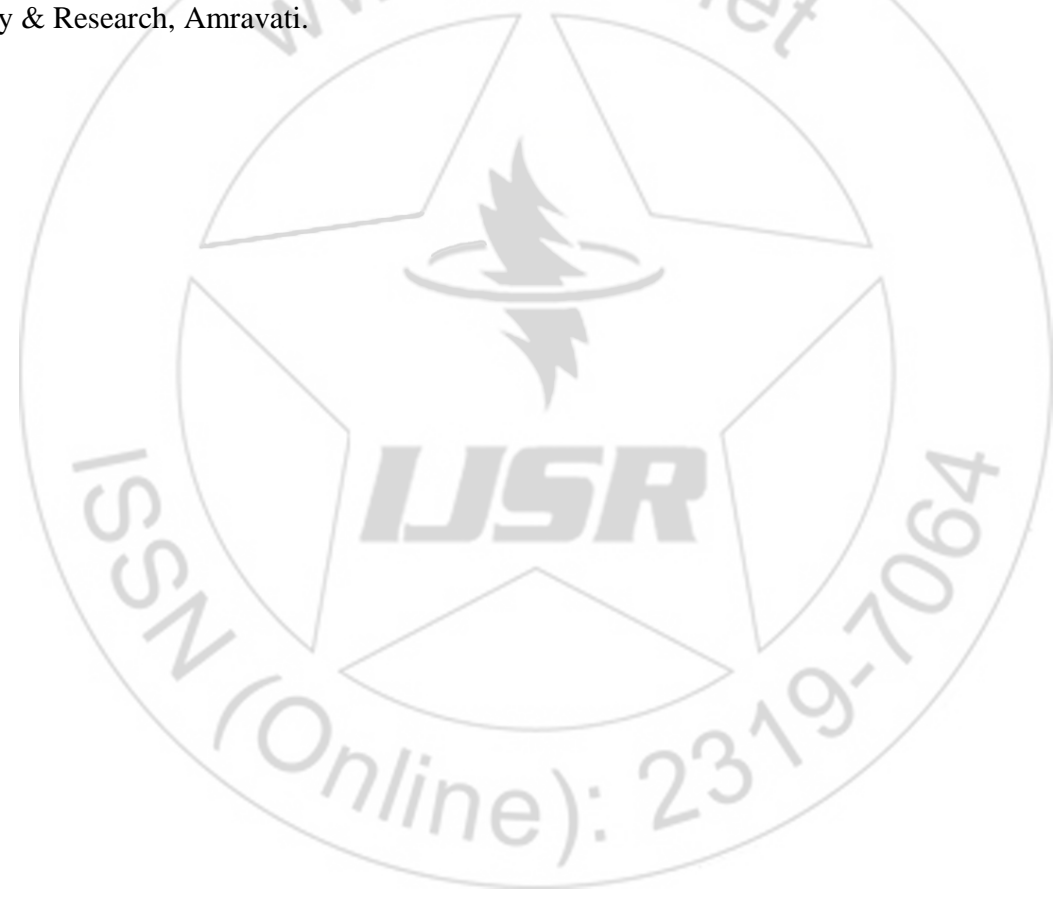

